\title{
Partition of oleic acid between the lymph and portal blood in rats having a diverted bile-pancreatic duct
}

\author{
BY Y. MATHIEU, C. CASELLI, A. BERNARD* AND H. CARLIER \\ Département de Nutrition, EA DRED 580, Ecole Nationale Supérieure de Biologie Appliquée à la \\ Nutrition et à l'Alimentation (ENS.BANA), Université de Bourgogne, 1 Esplanade Erasme, \\ 21000 Dijon, France
}

(Received 6 October 1993 - Revised 28 July 1994-Accepted 19 September 1994)

\begin{abstract}
The present study examines the suggestion that in the absence of adequate bile and pancreatic juice, which support the absorption from the gut of long-chain fatty acids into lymph, the fatty acids are absorbed directly into the portal blood. Oleic acid (18:1) partitioning between lymph and portal blood was investigated in intact and bile- and pancreatic juice-diverted rats. In a first set of experiments, 18:1 absorption from the gut into lymph and blood was studied by continuous recovery of the mesenteric lymph for $6 \mathrm{~h}$ and mesenteric portal venous blood for $1 \mathrm{~h}$. In a second set of experiments, esterification processes were investigated by study of the mucosal distribution of labelled lipids and by mono- and diacylglycerol acyltransferase ( $E C$ 2.3.1.22 and $E C$ 2.3.1.20 respectively) specific activities. In the bile- and pancreatic juice-diverted rats the absorption of labelled 18:1 into lymph was significantly reduced during the first $3 \mathrm{~h}$ of intraluminal infusion of this substrate. In such rats a compensatory absorption of labelled 18:1 into mesenteric portal blood was not observed. At $6 \mathrm{~h}$ after micellar lipidmixture infusion, the overload of lipids both in free form and as triacylglycerols persisting in the mucosa paralleled the lower acyltransferase specific activities observed in bile- and pancreatic juice-diverted rats. These studies demonstrate the absence of a previously proposed compensatory absorption of 18:1 into portal blood when absorption into lymph is impaired by an inadequate supply of bile and pancreatic juice.
\end{abstract}

Chyloportal partition: Bile: Acylglycerol acyltransferase

It is well established that long-chain fatty acids are absorbed as esters, mainly triacylglycerols (TG), and are integrated into lipoproteins as chylomicrons and VLDL via the lymph (Bloom et al. 1951; Greenberger et al. 1966). Short-chain fatty acids are transported free in the portal blood (Blomstrand, 1955; Carlier \& Bézard, 1975; Vallot et al. 1985). There is good evidence (Saunders \& Dawson, 1963; Brand \& Morgan, 1974; Shiau et al. 1979; Kotler et al. 1980) that biliary secretion is important for the esterification of fatty acids in the mucosa. There is a decrease in monoacylglycerol acyltransferase (MAGAT; EC 2.3.1.22) activity in rats whose bile duct has been diverted to the exterior (Tandon et al. 1972; Rodgers et al. 1973; Rodgers, 1975). Several groups have reported that there is a lack of lymphatic absorption of fatty acids in rats whose bile-pancreatic duct has been diverted (Saunders \& Dawson, 1963; Simmonds et al. 1968; Mansbach et al. 1985) and in bile-deficient humans (Blomstrand et al. 1969).

It has been suggested that long-chain fatty acids are absorbed into the mesenteric portal venous blood in the absence of bile (Hyun et al. 1967; Kayden \& Medick, 1969; Tso et al. 1981). We have therefore studied the fate of fatty acids and monoacylglycerols in rats lacking a normal flow of bile and pancreatic juice into the duodenum. The common bile-pancreatic duct of rats was diverted to the exterior, to produce a model in which

* For reprints. 
esterification should be reduced and absorption into the lymph impaired. We measured the absorption of radiolabelled 18:1 (oleic acid) into the blood and lymph, esterification and the activities of two key acyltransferases, MAGAT and diacylglycerol acyltransferase (DAGAT; EC 2.3.1.20) to determine whether the absorption of oleic acid into the portal blood was increased.

MATERIALS AND METHODS

Animals

French Regulations (no. 87848 and no. 03056) for the care and use of laboratory animals were followed. Male Wistar rats weighing $200-230 \mathrm{~g}$ (Centre d'élevage Dépré, St Doulchard, F18230, France) were housed in the animal room for $8 \mathrm{~d}$ before experiments. The animals were fed on a balanced diet $(40 \mathrm{~g}$ lipid $/ \mathrm{kg}$; UAR-Villemoisson sur Orge, F-91360, France) and had free access to tap water.

\section{Experiments}

Expt 1. Measurement of oleic acid absorbed into the lymph (group A). A total of eight rats were studied. Each rat was lightly anaesthetized with diethyl ether and a heparinized catheter (no. 1-F 75140 Biotrol, Paris, France) was inserted in the main mesenteric lymph duct (all rats). A second catheter (Biotrol no. 4) was placed in the duodenum (all rats), above the entry of the bile-pancreatic duct. The common bile pancratic duct of the experimental rats $(n 4)$ was cannulated (Biotrol no. 1). The rat was placed in a restraining cage and fasted for 16-24 h, but allowed access to saline $(7 \mathrm{~g} \mathrm{NaCl} / 1,2 \mathrm{~g} \mathrm{KCl} / \mathrm{l})$. The lipid micellar mixture was warmed to $37^{\circ}$ and introduced into the duodenum via the cannula. The lymph was collected over the following $6 \mathrm{~h}$ into a cooled $\left(4^{\circ}\right)$ tube moistened with $100 \mathrm{~g} / \mathrm{l}$ EDTA and the oleic acid content measured.

Expt 2. Measurement of oleic acid absorbed into the portal blood (group B). A group of eight rats were given bile-pancreatic duct cannulas as described for Expt 1 . The rats were fasted for $28 \mathrm{~h}$ but given saline to drink. The oleic acid passing into the portal blood was measured using the vascular perfusion technique of Bernard \& Carlier (1991) and Vallot $e t$ al. (1985). A catheter (Biotrol no. 4) was placed in the abdominal aorta and connected to a pressure detector (Statham P 23 DB; Narco-bio-systems, PO Box 12511 7651, Airport BLUD, Houston, Tx. 77017, USA) coupled to a Racia (Racia, Le Bouscat, F-33110, France) recorder to monitor arterial pressure. A metal cannula (Collin-Gentille no. 9; Moria, Antony, F-92160, France) was placed in the mesenteric portal vein. Heparinized blood obtained by heart puncture of rats of the same strain was continuously infused into the jugular vein by means of a peristaltic pump (Gilson minipulse (Gilson, Electronics France, Villers Le Bel, F-95400, France)) to compensate for blood loss. A $250 \mathrm{~mm}$ long intestinal loop was isolated in situ between two metal cannulas (Collin-Gentille no. 18); the upper cannula was placed just below the inlet of the common duct in the duodenum. Once the mesenteric portal vein was cannulated, heparinized blood at $37^{\circ}$ was perfused at a flow rate which maintained the blood pressure close to the initial level. When the pressure was stabilized, the lipid emulsion was introduced into the isolated intestinal loop and the blood was collected for $60 \mathrm{~min}$. At the end of the experiment the intestine was immediately removed, rinsed with $10 \mathrm{ml}$ saline at $0^{\circ}$ (kept for lipid analysis), opened longitudinally and the mucosa scraped off.

Lipids were extracted from the intestinal contents and the mucosa. A portion $(1 \mathrm{ml})$ of each blood fraction was used to extract bicarbonates; the acid-soluble products were extracted from a second portion $(1 \mathrm{ml})$. Lipids were extracted from the remainder.

Expt 3. Distribution of oleic acid in the mucosa, blood and liver (group C). Rats were anaesthetized with diethyl ether and a $250 \mathrm{~mm}$ duodeno-jejunal loop was isolated between two ligatures. The upper ligature was just above the inlet of the common duct into the 
duodenum. The test emulsion was infused in a catheter (Biotrol no. 4) placed in the isolated intestinal loop. The test lipid was left in place for $6 \mathrm{~h}$, during which time the rats were placed in restraining cages. The intestinal loop was then removed, rinsed with $10 \mathrm{ml}$ saline at $0^{\circ}$ (liquid kept for lipid analysis) and opened longitudinally. Blood samples were obtained from the abdominal aorta. Lipids were extracted from the intestinal contents, the scraped mucosa, blood samples and liver.

Expt 4. Measurement of mucosal mono- and diacylglycerol acyltransferases. The rats were assigned to one of six groups. There were two groups of controls, one fasted for $24 \mathrm{~h}$ (C1) and the other for $48 \mathrm{~h}$ (C2). Two groups of experimental animals were fasted for $24 \mathrm{~h}$, the rats in one group were given a bile-duct diversion only (BD1) while in the other group both the bile and pancreatic ducts were diverted (BPD1). Two further groups were fasted for $48 \mathrm{~h}$, one group had a bile-duct diversion (BD2) and the other had both a bile and pancreatic diversion (BPD2). All rats had free access to saline during the fasting period. At the end of this time the rats were killed and a $250 \mathrm{~mm}$ segment of duodenum-jejunum was removed for assay of MAGAT and DAGAT.

\section{Lipid mixture}

The lipid test mixture was $30 \mu \mathrm{mol}$ monopalmitoylglycerol, $30 \mu \mathrm{mol} 16: 0$ and $30 \mu \mathrm{mol}$ 18:1 (Nu Chek Prep, Elysian, MN, USA) plus $185 \mathrm{KBq}$ (specific activity: $195 \mathrm{KBq} / \mathrm{nmol}$ ) $\left[1{ }^{14} \mathrm{C}\right] 18: 1$ (purchased from the Commissariat à l'Energie Atomique, Saclay, F-91191, France). The lipids were emulsified with $60 \mu \mathrm{mol}$ sodium taurocholate (Sigma Chemical Co., St Louis, MO, USA) in $1.5 \mathrm{ml}$ saline solution before infusion into the duodenal lumen.

\section{Lipid extraction}

Lipids were extracted from the lymph, intestinal contents, mucosa, liver and blood samples with dimethoxy methane--methanol $(4: 1, \mathrm{v} / \mathrm{v})$ (Delsal, 1944). The individual lipid classes (phospholipids (PL), monoacylglycerols, diacylglycerols, free fatty acids (FFA) and TG were separated by TLC (Stahl et al. 1956). The radioactivity of the lipid extracts was determined.

\section{Bicarbonate extraction}

A blood sample $(1 \mathrm{ml})$ was haemolysed with saponin and $1 \mathrm{ml} 12 \mathrm{M}-\mathrm{HCl}$ was added to liberate $\mathrm{CO}_{2}$ which was trapped for $20 \mathrm{~h}$ with $0.5 \mathrm{ml}$ hyamine. The hyamine was then placed in a scintillation vial and the trapped radioactivity measured.

\section{Extraction of acid-soluble products}

Blood samples $(1 \mathrm{ml})$ were mixed with $4 \mathrm{ml} 1 \mathrm{M}-\mathrm{HClO}_{4}$ and the resulting precipitate removed by centrifugation for $10 \mathrm{~min}(3000 \mathrm{~g})$. The supernatant fraction was filtered through a $0.45 \mu \mathrm{m}$ Millipore filter and the radioactivity in a portion of filtrate was measured.

\section{Radioactivity measurement}

Lipid extracts and hyamine samples were counted in Permafluor III (Packard) diluted with xylene $(1: 9, \mathrm{v} / \mathrm{v})$. Acid-soluble products were counted in Instagel. The radioactivity was measured in a Packard Tricarb scintillation counter (Packard Prias PLD, Tricarb, Packard Instruments, Downers Grove, IL, USA).

\section{Microsomal acylglycerol acyltransferase activities}

The MAGAT and DAGAT activities in the absorptive-cell microsomes from four groups of experimental rats and two groups of control rats were measured by the method of Rodgers (1969) using palmitoyl-CoA. Duodeno-jejunum $(250 \mathrm{~mm})$ was rinsed with $10 \mathrm{ml}$ saline $(9 \mathrm{~g} \mathrm{NaCl} / 1)$, opened on ice and the mucosa scraped off. The mucosa was 
homogenized in $0.28 \mathrm{M}$-mannitol in $0.01 \mathrm{M}-\mathrm{Na}_{2} \mathrm{HPO}_{4}$, pH 7.4, plus $50 \mathrm{mm-EDTA,} \mathrm{pH} 7.4$ with a Polytron (Bioblock Scientific, Illkirch, F-67403, France) at $25000 \mathrm{rev} . / \mathrm{min}$ at $4^{\circ}$ and centrifuged twice at $8700 \mathrm{~g}$ for $20 \mathrm{~min}$ in a Beckman centrifuge (L8-55M, Beckman, Gagny, F-93220, France) at $4^{\circ}$. The pellets were discarded. The supernatant fraction was centrifuged at $105000 \mathrm{~g}$ at $4^{\circ}$ for $1 \mathrm{~h}$ in a Beckman ultracentrifuge (L8-55M). The supernatant fluid was discarded and the microsomal pellet resuspended using a Potter homogenizer $(1800 \mathrm{rev} . / \mathrm{min}$ for $20 \mathrm{~s})$ in $0.154 \mathrm{M}-\mathrm{KCl}$ in $0.01 \mathrm{M}-\mathrm{Na}_{2} \mathrm{HPO}_{4}, \mathrm{pH} 7.4(2 \mathrm{ml} / \mathrm{g}$ wet weight of original mucosa).

The assay medium was $0.6 \mathrm{ml} 0.1 \mathrm{M}$-Tris-HCl buffer, $\mathrm{pH} 8.0,0.06 \mathrm{ml} 100 \mathrm{~g} / 1$ bovine serum albumin (fraction V, Sigma Chemical Co.), 0.09 ml 0.01 M-DTNB (5,5'-dithiobis(2-nitrobenzoic acid) plus $75 \mathrm{nmol}$ 2-palmitoylglycerol (for MAGAT) or 1,2-dioleoylglycerol (for DAGAT) in $0.03 \mathrm{ml}$ ethanol $(950 \mathrm{ml} / 1), 150 \mathrm{nmol}$ palmitoyl-CoA in $0.06 \mathrm{ml} 0.01 \mathrm{M}-\mathrm{KH}_{2} \mathrm{PO}_{4}, \mathrm{pH} 5.0$. The reaction was begun by adding $0.03 \mathrm{mg}$ microsomal protein. The relative rates of deacylation (acyl-CoA $\rightarrow$ acid $+\mathrm{CoA})$ and acylation (monoacylglycerol + acyl-CoA $\rightarrow$ diacylglycerol + CoA (MAGAT) or diacylglycerol + acyl$\mathrm{CoA} \rightarrow \mathrm{TG}+\mathrm{CoA}$ (DAGAT)) were determined using two microcuvettes simultaneously. One contained the complete incubation medium and gave the CoA released by both acylation and deacylation. The other microcuvette contained the incubation medium minus the mono- or the diacylglycerol $(950 \mathrm{ml} / 1$ ethanol only). This microcuvette measured the CoA released by deacylation alone. The change in absorbance recorded in the 'deacylation' cuvette was subtracted from the change in absorbance in the other cuvette to obtain the rate of acylation. All assays were performed at $30^{\circ}$ and at $412 \mathrm{~nm}$ for at least $15 \mathrm{~min}$ using a Shimadzu spectrophotometer (UV-160 A, Roucaire, Velizy Villacoublay, F-78143, France). A molar absorptivity of $\mathrm{CoA}, 11622 / \mathrm{M}$ per $\mathrm{cm}$ was used to convert change in absorbance to nmol CoA released.

Proteins were estimated by the method of Smith et al. (1985) using bicinchoninic acid with bovine serum albumin (Sigma) as the standard.

\section{Calculations}

Results are expressed as fatty acid $\mu$ mol-equivalents calculated from the specific activity of the labelled fatty acid in the infusate. MAGAT and DAGAT specific activities are expressed as nmol CoA liberated/min per $\mathrm{mg}$ microsomal protein. Differences were compared using Student's unpaired comparisons test.

\section{RESULTS}

\section{Expt 1. Recovery of labelled 18:1 in the lymph}

The test lipid micellar mixture corresponded to 26140 (SEM 600) nmol oleic acid in the control rats and 27700 (SEM 900) nmol for the rats in the experimental group. There was significantly less labelled $18: 1$ in the lymph of bile-pancreatic juice-diverted rats $(10400$ (SEM 500) nmol) than in control rats $(17400$ (SEM 800$) \mathrm{nmol})(P<0.001)$. A total of 37.7 (SEM 2.5 ) \% of the infused radioactivity was recovered in the lymph of the test rats and 66.5 (SEM 3.7$) \%$ in the lymph of the controls.

The lymph absorption profile (Fig. 1) showed no change in the appearance of the radioactive absorption peak, but the labelled 18:1 lymph absorption in the test rats was low from the start of the absorption processes and continued during the first $2 \mathrm{~h}$ of lymph collection. The relative integration of labelled 18:1 into PL was significantly decreased in the test rats. As a consequence, the peak $\mathrm{TG}: \mathrm{PL}$ ratio was over fourfold higher in experimental rats (281 (SEM 78)) than in the control group (64 (SEM 17)). The 18:1 was mainly integrated into lymph TG in all rats $(92.8 \%)$ at the peak of absorption in controls and $85 \%$ in bile- and pancreatic juice-diverted rats, the labelled FFA never exceeded $2.3 \%$ in control and experimental groups at the peak of absorption. 


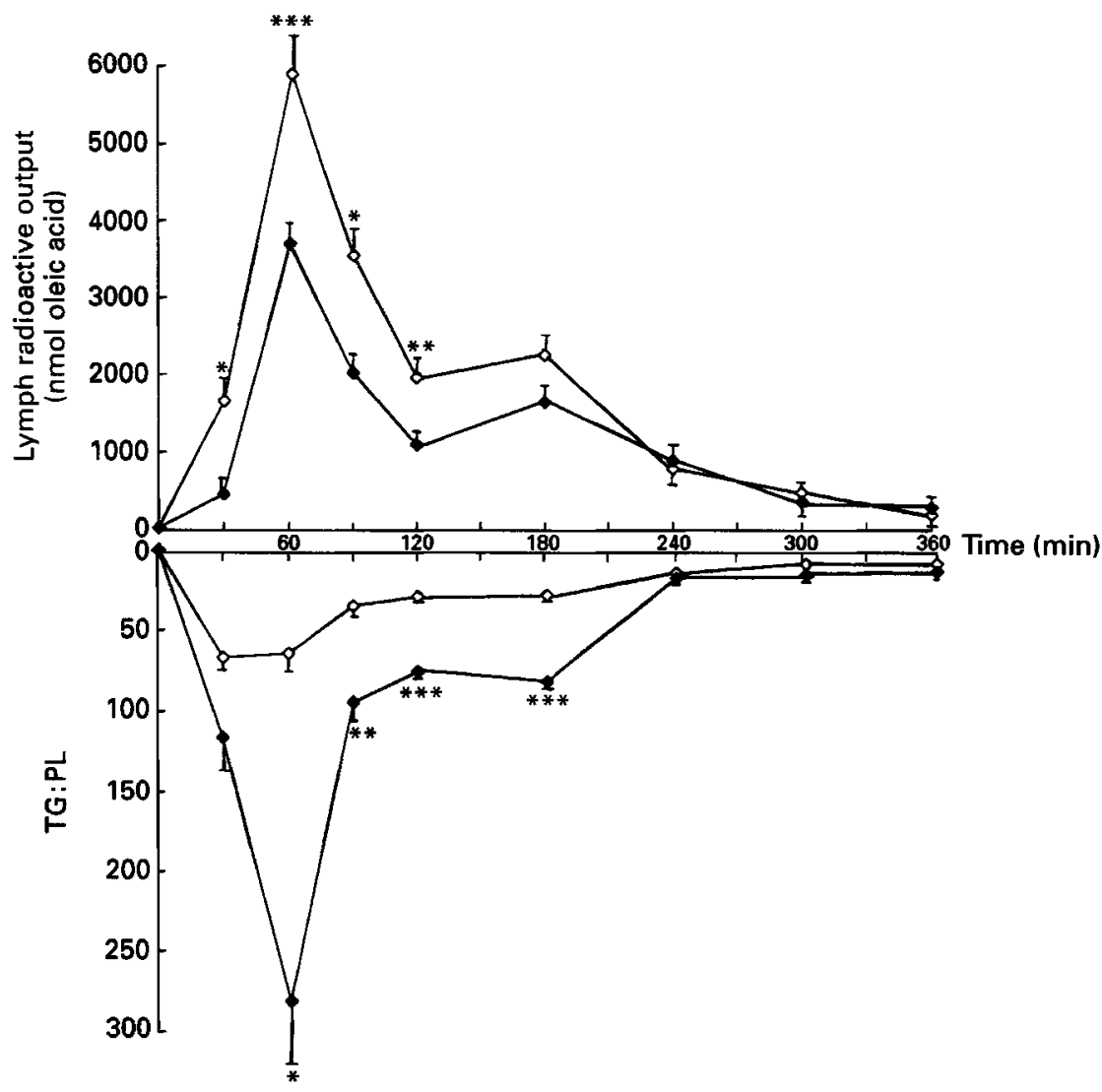

Fig. 1. Profile of lymph absorption in control $(\diamond)$ and bile- and pancreatic juice-diverted $(\diamond)$ rats. Values are expressed as nmol $\left[{ }^{14} \mathrm{C}\right] 18: 1$ recovered in the main mesenteric lymph duct and as the triacylglycerol:glycerophospholipid (TG:PL) ratio during the $6 \mathrm{~h}$ following duodenal infusion of $\left[{ }^{14} \mathrm{C}\right] 18: 1-16: 0$ - monopalmitoylglycerol (1:1:1 molar ratio; $90 \mu \mathrm{mol})$. Lymph radioactive lipid output was measured every $30 \mathrm{~min}$ for $2 \mathrm{~h}$ and then each hour for the remaining $4 \mathrm{~h}$ after the onset of the lipid infusion. Values are means for four rats per group, with their standard errors represented by vertical bars. Mean values for the two groups were significantly different: ${ }^{*} P<0.05,{ }^{* *} P<0.01$, ${ }^{* * *} P<0.001$.

\section{Expt 2. Recovery of labelled 18:1 in the mesenteric portal venous blood}

The labelled lipids infused were 23970 (SEM 1170) nmol for the control group and 24108 (SEM 526) nmol for the experimental group. The labelled lipids in the intestinal contents at the end of the experiment were 10597 (SEM 1220) nmol for the controls and 11323 (SEM 760) nmol for the experimental group. Thus uptake was the same for the two groups of rats: 12780 (SEM 580) nmol for the experimental rats and 13560 (SEM 1050) nmol for the controls. The amount of radioactivity recovered in the mesenteric portal venous blood of the experimental rats (1.3 (SEM 0.1)\%), was not significantly different from that of the controls $(1.5(\operatorname{sem} 0.2) \%)$. The radiolabelled catabolites (acid-soluble products and bicarbonates) resulting from the intramucosal catabolism were 134 (SEM 21) nmol in the controls and 95 (SEM 10) nmol in the experimental group and were not significantly different. The labelled ratios (catabolites:catabolites + lipids) were also not significantly different and within a range of 25 .

Profiles of portal venous blood absorption. Fig. 2 shows the $\left[{ }^{14} \mathrm{C}\right] 18: 1$ and radiolabelled 

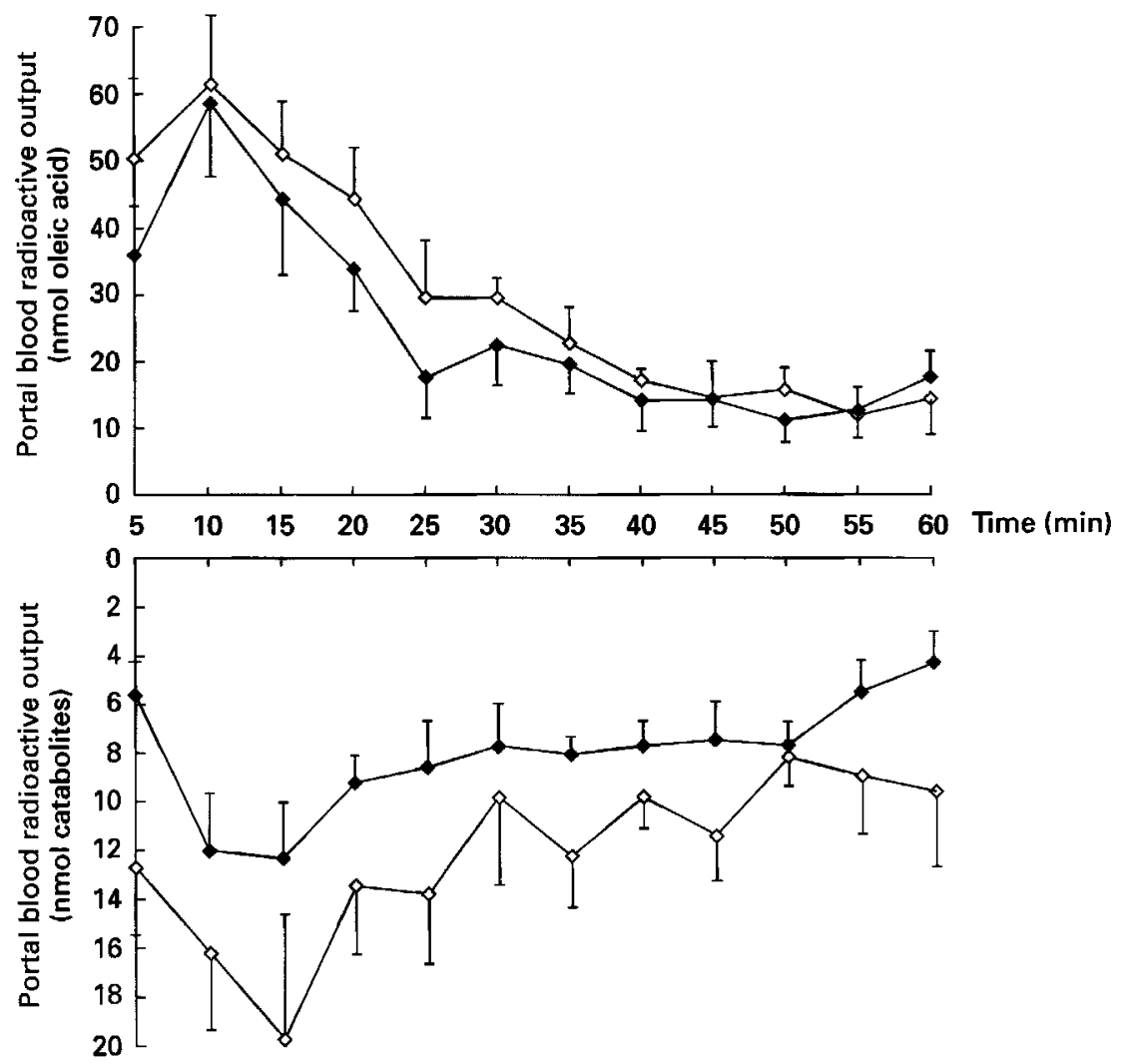

Fig. 2. Profiles of portal venous blood absorption in control $(\diamond)$ and bile- and pancreatic juice-diverted $(\diamond)$ rats Values are expressed as nmol $\left[{ }^{14} \mathrm{C}\right] 18: 1$ and radiolabelled catabolites (bicarbonates and acid-soluble products) recovered in mesenteric portal venous blood during the hour following duodenal infusion of $\left[{ }^{14} \mathrm{C}\right] 18: 1-16: 0-$ monopalmitoylglycerol (1:1:1 molar ratio; $90 \mu \mathrm{mol})$. Values are means for four rats per group, with their standard errors represented by vertical bars. Values were not significantly different between the two groups.

catabolites in mesenteric portal venous blood during the hour of blood collection. The blood absorption profiles of the two groups were similar. Absorption was the highest at the beginning of the radioactive lipid infusion and decreased until the twentieth minute. The appearance of catabolic products in the blood (acid-soluble products and bicarbonates) paralleled the appearance of radiolabelled fatty acids.

\section{Expt 3. Radioactive lipids in the mucosa, liver and blood samples}

Table 1 shows the radioactivity in the mucosa $1 \mathrm{~h}$ and $6 \mathrm{~h}$ after the infusion of test micellar mixture.

The amounts of radioactive lipid in the test mixture were 24290 (SEM 1290) nmol in the control group and 25240 (SEM 863) $\mathrm{nmol}$ in the experimental rats. There was no significant difference between the two groups after $1 \mathrm{~h}$ of absorption. There was 6220 (SEM 423) nmol of the 18:1 in the mucosa of the experimental rats and 7190 (SEM 550) nmol in the mucosa of the controls. The amounts of 18:1 remaining in the lumen were 1102 (SEM 390) nmol in the controls and 1788 (SEM 317) nmol in the experimental group. The amount subsequently taken up by the mucosa of the experimental rats was 23450 (SEM 1120 ) nmol (93 (SEM 2)\% of the infused radioactivity) while the amount taken up by the control rats mucosa was 
Table 1. Radioactivity recovered in the mucosa of rats $1 \mathrm{~h}$ and $6 \mathrm{~h}$ after duodenal infusions of radiolabelled oleic acid $\dagger$

(Mean values with their standard errors for two to five rats per group)

\begin{tabular}{|c|c|c|c|c|}
\hline & \multicolumn{2}{|c|}{ Controls } & \multicolumn{2}{|c|}{ BPD } \\
\hline & Mean & SE & Mean & SE \\
\hline $\begin{array}{l}\text { I h after lipid infusion } \\
\text { Lipids recovered in the mucosa (M) (nmol) (n 5) } \\
\text { M/infused radioactivity }(\%)(n 5)\end{array}$ & $\begin{array}{c}7190 \\
30 \cdot 4\end{array}$ & $\begin{array}{c}550 \\
3 \cdot 4\end{array}$ & $\begin{array}{r}6220 \\
24 \cdot 9\end{array}$ & $\begin{array}{c}423 \\
1.8\end{array}$ \\
\hline $\begin{array}{l}6 \mathrm{~h} \text { after lipid infusion } \\
\mathrm{M}(\mathrm{nmol})(n 5) \\
\mathrm{M} / \text { infused radioactivity }(\%)(n 5) \\
\text { Radiolabelled lipids recovered in the } \\
\text { liver/infused radioactivity }(\%)(n 4)\end{array}$ & $\begin{array}{l}1387 \\
5 \cdot 6 \\
1 \cdot 69\end{array}$ & $\begin{array}{l}277 \\
0.9 \\
0.09\end{array}$ & $\begin{array}{c}11342^{* * *} \\
44 \cdot 2^{* * *} \\
1 \cdot 28\end{array}$ & $\begin{array}{l}1242 \\
4.7 \\
0.05\end{array}$ \\
\hline $\begin{array}{l}\text { Radiolabelled lipids recovered in the systemic } \\
\text { blood samples }(1 \mathrm{ml}) / \text { infused radioactivity }(\%) \\
(n 2)\end{array}$ & 0.12 & 0.08 & 0.07 & 0.05 \\
\hline
\end{tabular}

BPD, bile- and pancreatic juice-diverted rats.

*** Mean values were significantly different from those of controls, $P<0.001$.

+ For details of procedures, see pp. 250-251.

23190 (SEM 990) nmol (96 (SEM 1)\% of the infused radioactivity). There was thus an overload of mucosal radioactivity in the experimental group (11342 (SEM 1242) nmol (44.9 (SEM 4.7$) \%$ of the infused radioactivity) compared with 1387 (SEM 277) nmol (5.6 (SEM 0.9$) \%$ of the infused radioactivity) in the control rats $6 \mathrm{~h}$ after the lipid infusion. There was a significant decrease in the mucosal radioactivity during the $1-6 \mathrm{~h}$ period in the control group (5.6 (SEM 0.9) \% of the radioactivity infused after $6 \mathrm{~h} v .30 .4$ (SEM 3.4 ) \% after $1 \mathrm{~h}$ ), but there was a significant overload of mucosal radioactivity in the test rats $(44.2$ (SEM 4.7$) \%$ of the radioactivity infused after $6 \mathrm{~h}$ and 24.9 (SEM 1.8$) \%$ after $1 \mathrm{~h}$ ). The portal blood transport of the radioactive lipids in the test (BPD) rats was not greater than in controls even as absorption continued $(0.07 \%$ of the radioactivity infused in the BPD rats $v .0 \cdot 12 \%$ of the radioactivity infused in the control group was recovered in the systemic blood samples), as confirmed by the liver radioactive lipids at $6 \mathrm{~h}(1.28$ (SEM 0.05$) \%$ radioactivity recovered in the BPD rats and 1.69 (SEM 0.09)\% in the controls).

Distribution of the radioactivity in the lipid classes in the intestinal mucosa (Fig. 3). At $1 \mathrm{~h}$ after the lipid infusion, although there was no significant difference between the amounts of radioactivity remaining in the mucosa of the test and control rats, the mucosal lipid partitioning showed a failure both of TG and PL esterification. There was less TG in the BPD rats (833 (SEM 133) nmol) than in the controls (1836 (SEM 141) nmol) with a calculated TG:FFA ratio of $0 \cdot 16$, i.e. half that of the control group. The decrease in PL was similar : 96 (SEM 10) nmol in the experimental animals and 236 (SEM 54) nmol in the control rats.

There was an overload of the FFA and TG radioactivity in the mucosa of the test rats during the $1-6 \mathrm{~h}$ period. The PL remaining in the mucosa $6 \mathrm{~h}$ after lipid infusion were of the same order in the two groups: 346 (SEM 59) nmol in the experimental group and 406 (SEM 47) nmol in controls. This is as in the control and BPD groups after $1 \mathrm{~h}$ of absorption.

Compared with the control and experimental groups after $1 \mathrm{~h}$ of absorption and with the control rats $6 \mathrm{~h}$ after lipid infusion, the test rats had an overload of FFA after $6 \mathrm{~h}$ of absorption (4632 (SEM 736) nmol v. 210 (SEM 91) nmol in the respective controls). Similarly, 

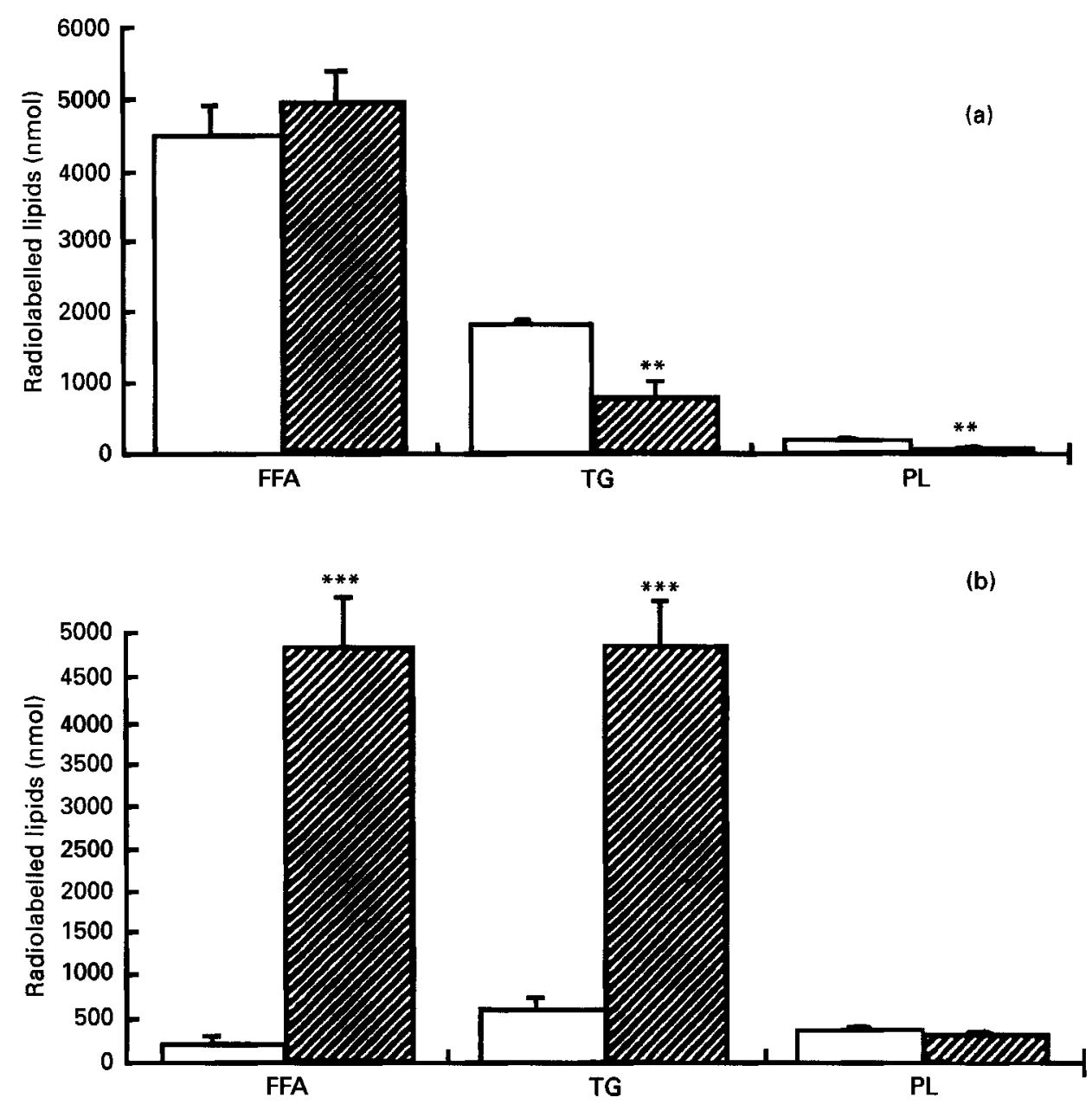

Fig. 3. Distribution of labelled lipids in the mucosa of control $(\square)$ and bile- and pancratic juice-diverted ( $\square)$ rats (a) $1 \mathrm{~h}$ and (b) $6 \mathrm{~h}$ after duodenal lipid infusion. Results are expressed as nmol $\left[{ }^{14} \mathrm{C}\right] 18: 1$ recovered in free fatty acids (FFA), triacylglycerols (TG) and glycerophospholipids (PL) after a duodenal infusion of $90 \mu \mathrm{mol}\left[{ }^{14} \mathrm{C}\right] 18: 1-16: 0$ - monopalmitoylglycerol (1:1:1 molar ratio). Values are means for five rats per group, with their standard errors represented by vertical bars. Mean values were significantly different from those of controls, ${ }^{* *} P<0.01,{ }^{* * *} P<0.001$.

there was a TG overload in the experimental rats $6 \mathrm{~h}$ after lipid infusion (4962 (SEM 597) nmol v. 624 (SEM 157) nmol in controls) with a calculated TG:FFA ratio twofold lower for the BPD rats.

These results showed not only a failure in TG esterification during the two absorption time periods but also an impairment in the secretion of synthesized TG.

\section{Expt 4. Mono- and diacylglycerol acyltransferase activities}

The MAGAT and DAGAT specific activities of the mucosal microsomes are summarized in Fig. 4. MAGAT activity was not affected by 24 or $48 \mathrm{~h}$ fasting in either the controls or the experimental rats. Diversion of bile with or without pancreatic juice-diversion significantly decreased the enzyme activity (the mean MAGAT activities dropped to 

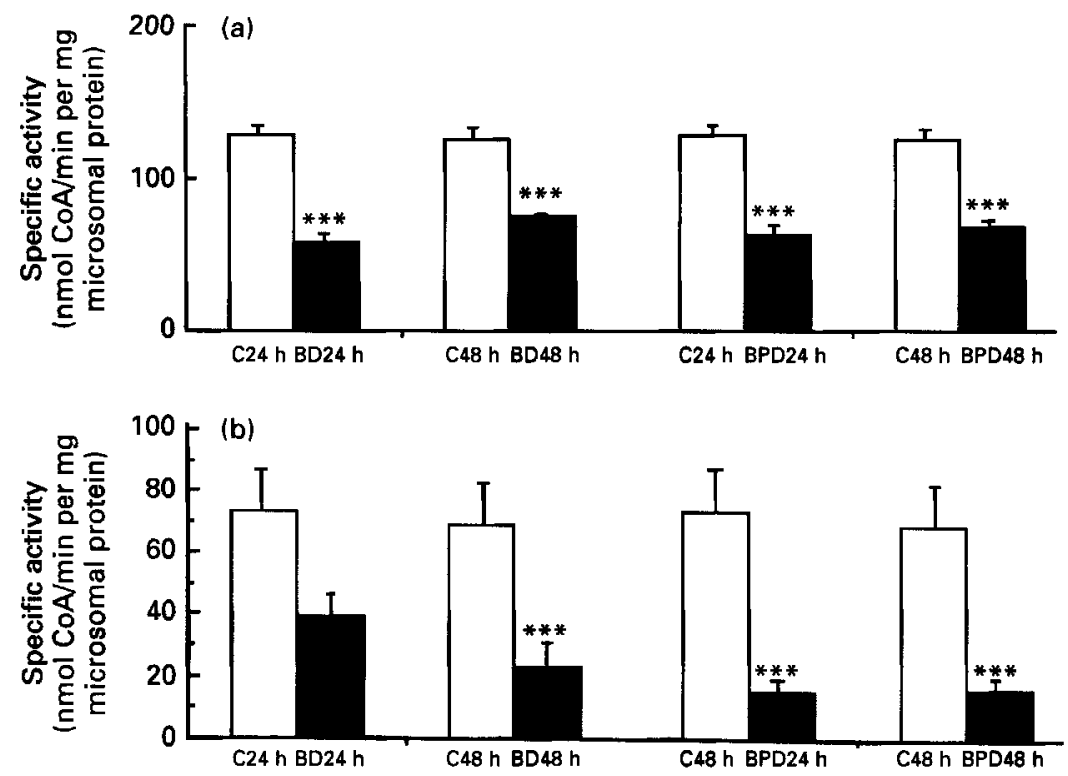

Fig. 4. Specific activities of (a) monoacylglycerol acyltransferase (EC 2.3.1.22) and (b) diacylglycerol transferase (EC 2.3.1.20) in the mucosal microsomes of control (C, $\square$ ) and bile-diverted (BD) or bile- and pancreatic juicediverted (BPD) rats $(\square)$ after 24 or $48 \mathrm{~h}$ of diversion. Activities are expressed as nmol liberated Coenzyme A/min per mg microsomal protein. Values are means for four rats per group, with their standard errors represented by vertical bars. ${ }^{* * *}$ Mean values were significantly different from those for controls, $P<0.001$.

$44.4-59.4 \%$ of the respective controls). Although the deviation was greater for DAGAT activity, the same decreases were seen, but with a more drastic effect of bile and pancreatic juice diversion (the DAGAT activities were $20.5-53 \cdot 4 \%$ of the respective controls).

\section{DISCUSSION}

Biliary secretions influence both the luminal and the enterocyte phases of lipid absorption. The present study examined the enterocyte phase. Because the test rats had no luminal TG hydrolysis due to the lack of bile and pancreatic juice, the test lipid micellar mixture contained a monoacylglycerol (monopalmitoylglycerol) and two fatty acids (18:1 and 16:0). Radiolabelled 18:1 was used to follow fatty acid enterocyte esterification and the fate of 18:1 absorbed. The lipid mixture was infused as an emulsion in $1.5 \mathrm{ml}$ saline sodium taurocholate $(60 \mu \mathrm{mol})$ so as not to disturb enterocyte uptake and to allow lipid molecules to overcome the resistance of the unstirred water layer. The absence of significant differences between uptake of lipids by control and experimental groups showed that the quantity of sodium taurocholate used allowed oleic acid to cross the unstirred water layer.

Preliminary experiments (Jacquemot et al. 1989) showed that infusion of a single dose of $90 \mu \mathrm{mol}$ lipids into the duodenum gave optimal absorption conditions for investigating their lymphatic absorption. The control group's lymph recovery of 65.5 (SEM 3.7) \% of the infused radioactivity is well within the range of published values (Tso et al. 1977; BennettClark, 1978). Under these conditions, peak absorption occurred in the initial $90 \mathrm{~min}$ after the onset of infusion.

In the light of the results of Morgan (1966), and the observations of Mansbach et al. (1985) on the quantity of lipids used, experiments were performed on the day after surgery (Mansbach et al. 1985). Indeed we checked that there was no significant difference in the 
lymph lipid output of control and experimental groups, particularly in bile- and pancreatic juice-diverted-rats, whether the experiment was carried out on the first or the second day after the operation.

The absorption of labelled 18:1 in the portal venous blood was investigated in rats using $250 \mathrm{~mm}$ duodeno-jejunal loops, because this is the major site of lipid absorption (Rodgers \& Bochenek, 1970; Brand \& Morgan, 1974), and because uptake of this amount of lipid and chylomicron formation is confined to the jejunum (Bennett-Clark, 1978). The use of these relatively short loops did distort differences between the test and control rats.

Preliminary experiments (results not shown) were conducted on the entire intestine with similar amounts of radioactivity uptake. There was no significant overload in the mucosa $1 \mathrm{~h}$ after the duodenal lipid infusion: $34.1 \%$ of the radioactivity infused was recovered in the entire intestinal mucosa of control rats and $34.1 \%$ in the $250 \mathrm{~mm}$ isolated duodenojejunal loop. Thus, the results of the mucosal contents are considered to be valid.

The vascular perfusion technique (Bernard \& Carlier, 1984) was used to monitor the uptake of labelled 18:1 into the portal vein of bile- and pancreatic juice-diverted-rats, and to test the proposals of several authors that it is increased in lymph absorption impairment (Saunders \& Dawson, 1963; Hyun et al. 1967; Blomstrand et al. 1969; Kayden \& Medick, 1969; Tso et al. 1981). Many studies have shown that this is a reliable technique. We used it to show a comparable ratio of chyloportal partition betwen 10:0 and 18:1 (Bernard \& Carlier, 1984; Vallot et al. 1985) to that obtained by Hyun et al. (1967) using several venous punctures of mesenteric portal blood. Differences in blood absorption of fatty acids according to their chain length and unsaturation (Bernard \& Carlier, 1991) have also been demonstrated with this technique. The chyloportal partition of $18: 2$ agreed with the length of the carbon chain and showed that the relative blood absorption increased with a reduction in the amount of 18:2 (McDonald et al. 1980).

The absorption of labelled 18:1 into the lymph was impaired as early as the start of lymphatic output and particularly during the first three half-hours following the onset of the lipid duodenal infusion in bile and pancreatic juice-diverted-rats. It was $44 \%$ lower than the controls. The fatty acids absorbed via the portal pathway remained free while the fatty acids recovered in the lymph were esterified and integrated into lipoproteins. Thus, as esterification in enterocytes is impaired, diversion towards blood absorption during the first hour of absorption is not unreasonable. At $1 \mathrm{~h}$ after lipid administration there was no difference between the radioactivity recovered in the blood samples of any groups $(1.5$ (SEM 0.2$) \%$ of the radioactivity infused was recovered in blood lipids in the controls and 1.3 (SEM 0.1$) \%$ in the experimental group). Some experiments (results not shown) were carried out for $2 \mathrm{~h}$ but there was still no significant difference between the control and experimental groups. Because large quantities of blood were needed from donor rats, all experiments were limited to $1 \mathrm{~h}$ in group $\mathrm{B}$. The oleic acid may perhaps have been absorbed by the blood pathway later in the experimental group.

Further experiments were carried out for $6 \mathrm{~h}$ after the lipid infusion. This was a period when the mucosa was overloaded with oleic acid in its free form and when there was no significant difference in the lymph. Studies on the liver and systemic blood samples showed no increase in portal transport in BPD rats compared with control rats.

Our experimental conditions allowed us to confirm the major observations reported previously and verified by several authors, apart from some differences due to different experimental designs. The essential point is the very significant decrease in labelled 18:1 lymph absorption throughout the entire absorption period and particularly at the beginning. Thus, in contrast with Morgan (1966), but in agreement with many other authors (Saunders \& Dawson, 1963; Simmonds et al. 1968; Rampone, 1970; BennettClark, 1978), absorption was profoundly impaired, although fatty acids were presented to 
the mucosa in a micellar phase, in free form and in the presence of a monoacylglycerol to preserve and favour the enterocyte monoacylglycerol pathway of re-esterification, and although uptake was not impaired. This suggests that the effect mainly involves enterocyte events.

Labelled 18:1 was recovered in the lymph principally in the esterified form, especially as TG. There was only a slight decrease in the peak absorption in bile- and pancreatic juicediverted rats. In agreement with Morgan (1966), the percentage of 18:1 persisting in free form in lymph was, on average, 2.3 (SEM 0.9 ) \% at the peak absorption in all the groups. As mentioned by Morgan (1966), the increase in free 18:1 recovered in lymph of bile fistulated rats by Saunders \& Dawson (1969) may have been due to the use of free 18:1 instead of TG as in the work of Morgan (1966) and of FFA plus monoacylglycerols in the present study. This would seem to indicate that failure of esterification did not increase the lymphatic uptake of free long-chain fatty acids, although there was a small but real increase in the percentage of FFA in the mucosa and in experimental group A compared with control group B, which was particularly emphasized in the mucosa of experimental group C.

The second observation previously mentioned by several authors, besides conflicting findings resulting from different experimental conditions and quantities of lipids (Simmonds et al. 1968), was the failure of mucosal esterification. As reported in most published papers, this resulted in an overload of lipids in the mucosa with the uptake being unaffected (Rampone, 1970; Tso et al. 1981). The mucosal overload was amplified differently according to the design (groups A, B or C) and concerned both 18:1 in its free form (O'Doherty et al. 1973) and TG (Tso et al. 1981).

These observations have led several authors to suggest that intestine-mucosal esterification is stimulated by bile salts (Saunders \& Dawson, 1963; Rampone, 1970) particularly through the monoacylglycerol pathway (Shiau et al. 1979; Kotler et al. 1980). O'Doherty et al. (1973) pointed out the role played by biliary and dietary phosphatidylcholine in fat absorption by providing precursors of phosphatidylcholine for chylomicron formation. This has been confirmed by other workers (Rodgers, 1975; Shiau et al. 1978, 1979; Kotler et al. 1980). Most showed that luminal phosphatidylcholine improved the TG lymphatic output in bile-diverted rats (Bennett-Clark, 1978). Tso et al. (1977) and Bennett-Clark (1978) demonstrated the role of biliary lecithin in chylomicron secretion into lymph, and Tso et al. (1981) and Mansbach et al. (1985) restored lymph absorption by adding phosphatidylcholine to the infusates.

In our case the readjustment of labelled glycerophospholipids $6 \mathrm{~h}$ after the lipid infusion in bile and pancreatic juice-diverted-rats $v$. control rats might have been due to de novo synthesis through the $\alpha$-phosphatidic pathway, but this synthesis remained insufficient to allow the release of mucosal TG in the experimental groups. This highlights the major role played by glycerophospholipids both for the coating of chylomicrons and the turnover of enterocyte membranes associated with lipoprotein exocytosis (O'Doherty et al. 1973).

The decrease of enterocyte esterification was studied by measuring the acyltransferase activity involved in the monoacylglycerol pathway. The results obtained in this study are in complete agreement with the literature (Rodgers et al. 1972, 1973; Singh et al. 1972; Tandon et al. 1972; Brand \& Morgan, 1974; Rodgers, 1975; Coleman \& Bell, 1976; Grigor \& Bell, 1982; Hoffman \& Kuksis, 1982). These results also agree with the biochemical analysis of the fate of labelled $18: 1$ in the mucosa and with the lymph radioactivity recoveries.

Thus, despite the fact that the results obtained in this present study agree with previously published work on changes in enterocyte esterification and lymph absorption, we have not shown that there is any compensatory mesenteric portal venous blood transport of labelled 
18:1 in bile- and pancreatic juice-diverted rats. There was an overload of labelled lipids, both in free form and in the TG state, in the mucosa $6 \mathrm{~h}$ after the test load which remained so for a modest quantity of lipids and a very long time period after the peak of absorption. In addition to their role at the luminal level, bile salts seem to be important for esterification, while glycerophospholipids may play a major role in chylomicron organization and exocytosis.

The authors thank M. C. Monnot for her valuable technical assistance.

\section{REFERENCES}

Bennett-Clark, S. (1978). Chylomicron composition during duodenal triglyceride and lecithin infusion. American Journal of Physiology 235, E183-E190.

Bernard, A. \& Carlier, H. (1984). Métabolisme intraentérocytaire et absorption par la voie sanguine des acides caprique et oléique chez le rat témoin et traité par l'actidione-cycloheximide. (Enterocyte metabolism and blood absorption of capric and oleic acids in control and actidione-cycloheximide-treated rats.) Reproduction Nutrition Developpement 24, 543-556.

Bernard, A. \& Carlier, H. (1991). Absorption and intestinal catabolism of fatty acids in the rat: effect of chain length and unsaturation. Experimental Physiology 76, 445-455.

Blomstrand, R. (1955). Transport form of decanoic acid-1 $1{ }^{14} \mathrm{C}$ in the lymph during intestinal absorption in the rat. Acta Physiologica Scandinavica 34, 67-70.

Blomstrand, R., Carlberger, G. \& Forsgren, L. (1969). Intestinal absorption and metabolism of ${ }^{14} \mathrm{C}$-labelled fatty acids in the absence of bile in humans. Acta Chirurgica Scandinavica 135, 329-339.

Bloom, B., Chaikoff, I. L. \& Reinhardt, W. O. (1951). Intestinal lymph as pathway for transport of absorbed fatty acids of different chain lengths. American Journal of Physiology 166, 451-455.

Brand, S. J. \& Morgan, R. G. H. (1974). Fatty acid uptake and esterification by proximal and distal intestine in bile fistula rats. Biochimica et Biophysica Acta 369, 1-7.

Carlier, H. \& Bezard, J. (1975). Electron microscope autoradiographic study of intestinal absorption of decanoic and octanoic acids in the rat. Journal of Cell Biology 65, 383-397.

Coleman, R. \& Bell, R. M. (1976). Triacylglycerol synthesis in isolated fat cells. The Journal of Biological Chemistry 251, 4537-4543.

Delsal, J. L. (1944). Nouveau procédé d'extraction des lipides du sérum par le méthylal. Application aux microdosages du cholestérol total, des phospholipides et des protéines. (New extraction method of serum lipids by methylal. Application to microassays of total cholesterol, phospholipids and proteins.) Bulletin de la Société de Chimie Biologique 26, 99-105.

Greenberger, N. J., Rodgers, J. B. \& Isselbacher, K. J. (1966). Absorption of medium and long chain triglycerides: factors influencing their hydrolysis and transport. Journal of Clinical Investigation 45, 217-227.

Grigor, M. R. \& Bell, R. M. (1982). Separate monoacylglycerol and diacylglycerol acyltransferases function in intestinal triacylglycerol synthesis. Biochimica et Biophysica Acta 712, 464-472.

Hoffman, A. G. D. \& Kuksis, A. (1982). Relative acylglycerolacyltransferase activities in homogenates of enzymically dispersed rat jejunal villus and crypt cells. Biochimica et Biophysica Acta 710, 53-62.

Hyun, S. A., Vahouny, G. V. \& Treadwell, C. R. (1967). Portal absorption of fatty acids in lymph- and portal vein-cannulated rats. Biochimica et Biophysica Acta 137, 296-305.

Jacquemot, D., Pavero, C., Bernard, A., Caselli, C. \& Carlier, H. (1989). Luminal lipid dose, lymph absorption and chylomicron formation. In Premier Congrès Eurolipid, ETIG ed., Paris, vol. 2, pp. 875-882.

Kayden, H. J. \& Medick, M. (1969). The absorption and metabolism of short and long chain fatty acids in puromycin-treated rats. Biochimica et Biophysica Acta 176, 37-43.

Kotler, D. P., Shiau, Y.-F. \& Levine, G. M. (1980). Effects of luminal contents on jejunal fatty acid esterification in the rat. American Journal of Physiology 238, G414-G418.

McDonald, G. B., Saunders, D. R., Weidman, M. \& Fischer, L. (1980). Portal venous transport of long-chain fatty acids absorbed from rat intestine. American Journal of Physiology 239, G141-G150.

Mansbach, C. M., Arnold, A. \& Cox, M. A. (1985). Factors influencing triacylglycerol delivery into mesenteric lymph. American Journal of Physiology 249, G642-G648.

Morgan, R. G. H. (1966). The effect of operation and the method of feeding on the lymphatic transport of fat by bile fistula rats. Quarterly Journal of Experimental Physiology 51, 33-41.

O'Doherty, P. J. A., Kakis, G. \& Kuksis, A. (1973). Role of luminal lecithin in intestinal fat absorption. Lipids 8, 249-255.

Rampone, A. J. (1970). Intestinal absorption of micellar lipid in normal and bile deficient rats. Proceedings of the Society for Experimental Biology and Medicine 135, 666-670.

Rodgers, J. B. (1969). Assay of acylCoA-monoglyceride acyltransferase from rat small intestine using continuous recording spectrophotometry. Journal of Lipid Research 10, 427-432. 
Rodgers, J. B. (1975). Lipid absorption in bile fistula rats. Lack of a requirement for biliary lecithin. Biochimica et Biophysica Acta 398, 92-100.

Rodgers, J. B. \& Bochenek, W. (1970). Localization of lipid reesterifying enzymes of the rat small intestine. Effects of jejunal removal on ileal enzyme activities. Biochimica et Biophysica Acta 202, 426-435.

Rodgers, J. B., Tandon, R. \& Fromm, H. (1972). Acyl-CoA synthetase for long-chain fatty acids in rat small bowel and the influence of diets containing different compositions of fatty acids on intestinal lipid reesterifying enzyme activities. Biochimica et Biophysica Acta 270, 453-462.

Rodgers, J. B., Tandon, R. \& O'Brien, R. J. (1973). Activities of lipid reesterifying enzymes in jejunal microsomes of bile fistula rats. Attempts to correlate enzyme activities with microsomal phospholipid content. Biochimica et Biophysica Acta 326, 345-354.

Saunders, D. R. \& Dawson, A. M. (1963). The absorption of oleic acid in the bile fistula rat. Gut 4, 254-260.

Shiau, Y.-F., Levine, G. \& Kotler, D. (1978). Effect of pancreatio-biliary secretion and luminal content on intestinal fatty acid esterification. Gastroenterology 74, 1093.

Shiau, Y.-F., Umstetter, C., Kendall, K. \& Koldovsky, O. (1979). Development of fatty acid esterification mechanisms in rat small intestine. American Journal of Physiology 237, E399-E403.

Simmonds, W. J., Redgrave, T. G. \& Willix, R. L. S. (1968). Absorption of oleic and palmitic acids from emulsions and micellar solutions. Journal of Clinical Investigation 47, 1015-1025.

Singh, A., Balint, J. A., Edmonds, R. H. \& Rodgers, J. B. (1972). Adaptive changes of the rat small intestine in response to a high fat diet. Biochimica et Biophysica Acta 260, 708-715.

Smith, P. K., Krohn, R. I., Hernanson, G. T., Mallia, A. K., Gartner, F. H., Provenzano, M. D., Fujimoto, E. K., Goeke, N. M., Olson, B. J. \& Klenk, D. C. (1985). Measurement of protein using Bicinchoninic acid. Analytical Biochemistry 150, 76-85.

Stahl, E., Shroter, G., Kraft, G. \& Renz, R. (1956). Thin-layer chromatography (the method affecting factors and a few examples of applications). Pharmazie 11, 633-637.

Tandon, R., Edmonds, R. H. \& Rodgers, J. B. (1972). Effect of bile diversion on the lipid-reesterifying capacity of the rat small bowel. Gastroenterology 63, 990-1003.

Tso, P., Balint, J. A. \& Simmonds, W. J. (1977). Role of biliary lecithin in lymphatic transport of fat. Gastroenterology 73, 1362-1367.

Tso, P., Kendrick, H., Balint, J. A. \& Simmonds, W. J. (1981). Role of biliary phosphatidylcholine in the absorption and transport of dietary triolein in the rat. Gastroenterology 80, 60-65.

Vallot, A., Bernard, A. \& Carlier, H. (1985). Influence of the diet on the portal and lymph transport of decanoic acid in rats. Simultaneous study of its mucosal catabolism. Comparative Biochemistry and Physiology 82A, 693-699. 